\title{
STEAP4: its emerging role in metabolism and homeostasis of cellular iron and copper
}

\author{
Rachel T Scarl1,2, C Martin Lawrence ${ }^{3}$, Hannah M Gordon ${ }^{1,2}$ and Craig S Nunemaker1,2 \\ 1Diabetes Institute, Heritage College of Osteopathic Medicine, Ohio University, Athens, Ohio, USA \\ 2Department of Biomedical Sciences, Heritage College of Osteopathic Medicine, Ohio University, Athens, Ohio, USA \\ 3Department of Chemistry and Biochemistry, Montana State University, Bozeman, Montana, USA
}

Correspondence

should be addressed

to C S Nunemaker

Email

nunemake@ohio.edu

\begin{abstract}
Preserving energy homeostasis in the presence of stressors such as proinflammatory cytokines and nutrient overload is crucial to maintaining normal cellular function. Six transmembrane epithelial antigen of the prostate 4 (STEAP4), a metalloreductase involved in iron and copper homeostasis, is thought to play a potentially important role in the cellular response to inflammatory stress. Genome-wide association studies have linked various mutations in STEAP4 with the development of metabolic disorders such as obesity, metabolic syndrome and type 2 diabetes. Several studies have shown that expression of Steap4 is modulated by inflammatory cytokines, hormones and other indicators of cellular stress and that STEAP4 may protect cells from damage, helping to maintain normal metabolic function. STEAP4 appears to be particularly relevant in metabolically oriented cells, such as adipocytes, hepatocytes and pancreatic islet cells. These cells struggle to maintain their function in iron or copper overloaded states, presumably due to increased oxidative stress, suggesting STEAP4's role in metal homeostasis is critical to the maintenance of cellular homeostasis in general, and in preventing the onset of metabolic disease. In this review, we explore genetic associations of STEAP4 with metabolic disorders, and we examine STEAP4 tissue expression, subcellular localization, regulation, structure and function as it relates to metabolic diseases. We then examine how STEAP4's role as a regulator of cellular iron and copper may relate to type 2 diabetes.
\end{abstract}

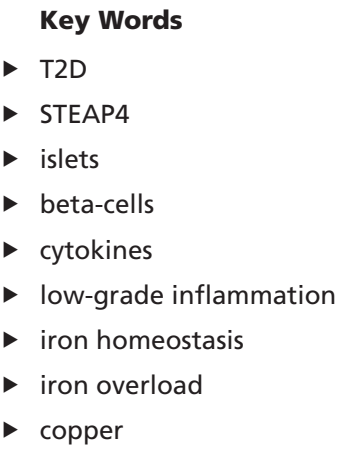

Journal of Endocrinology (2017) 234, R123-R134

\section{Introduction}

Six transmembrane epithelial antigen of the prostate 4 (STEAP4) is an integral membrane protein that functions as a metalloreductase involved in the transport of copper and iron (Ohgami et al. 2006, Grunewald et al. 2012). The expression of Steap4, also known as TNF $\alpha-$ induced adipose-related proteins (TIARP) (Moldes et al. 2001) or six transmembrane protein of prostate 2 (STAMP2) (Korkmaz et al. 2005), is modulated in response to inflammation, and metabolism of fatty acids and glucose. Several studies have identified genetic variants in STEAP4 that are associated with numerous metabolic disorders. In line with the hypothesis that defects in STEAP4 are implicated in metabolic disorders, expression of Steap4 is associated with protection against inflammatory-mediated cellular damage. How the metalloreductase actions of STEAP4 may or may not 
be associated with STEAP4's putative protective effects are discussed below.

\section{STEAP4 structure and function}

\section{STEAP4 is a metalloreductase}

Reduction of extracellular $\mathrm{Fe}^{3+}$ to $\mathrm{Fe}^{2+}$ and $\mathrm{Cu}^{2+}$ to $\mathrm{Cu}^{1+}$ are prerequisites for the transport of each of these metals across the membrane, into the cell. Steap4 and the related Steap2 and Steap3 family members are integral membrane metalloreductases that move electrons from cytosolic NADPH to extracellular iron or copper. STEAP4 (Fig. 1) is composed of two domains, an N-terminal oxidoreductase domain present on the cytoplasmic face and, as its name implies (STEAP4: six transmembrane epithelial antigen of the prostrate 4), a C-terminal transmembrane domain composed of six membrane spanning $\alpha$-helices that envelop a single heme-binding site (Ohgami et al. 2005, Kleven et al. 2015). Early hypotheses based upon homology to other ferric and oxidoreductases suggested the oxidoreductase domain would catalyze electron flow from NADPH to an unidentified flavin, that would then donate electrons

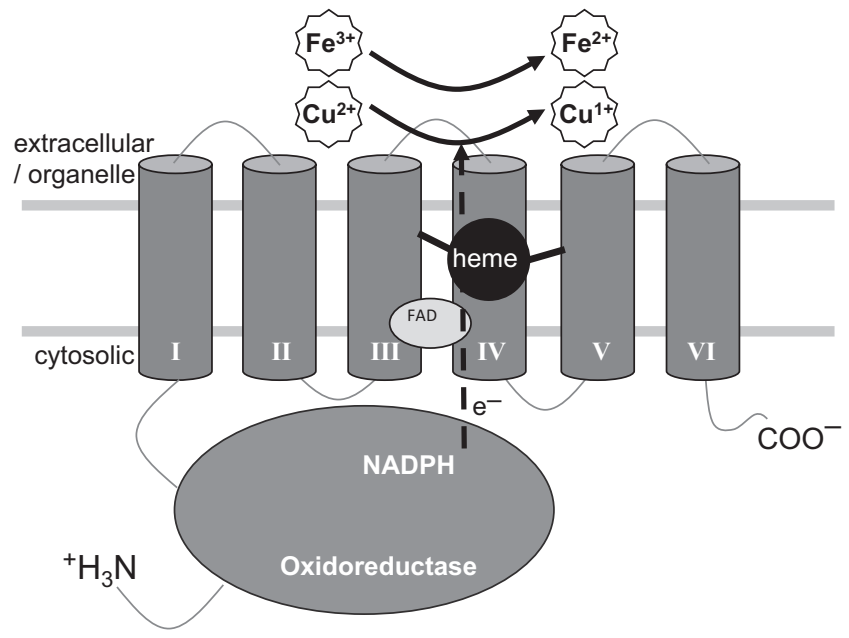

Figure 1

Structure and function of STEAP4. Steap4 is composed of two domains, an $\mathrm{N}$-terminal oxidoreductase domain, and a C-terminal transmembrane domain composed of six alpha-helices that coordinate a single heme. The $\mathrm{N}$-terminal oxidoreductase domain draws two electrons from cytoplasmic NADPH and passes these to FAD at the cytosolic face of the transmembrane domain, reducing it to $\mathrm{FADH}_{2}$. $\mathrm{FADH}$, in turn, passes electrons, one at a time, through the heme in the transmembrane domain, to the cell surface metal-binding site where $\mathrm{Fe}^{3+}$ is reduced to $\mathrm{Fe}^{2+}$, or $\mathrm{Cu}^{2+}$ to $\mathrm{Cu}^{1+}$, a prerequisite for transport into the cell or across organelle membranes. to the transmembrane domain where they would move through the heme group to an extracellular metal-binding site, reducing iron and copper (Ohgami et al. 2005, 2006).

Mutational, kinetic and crystallographic analyses now definitively show that the N-terminal domain does indeed bind and oxidize NADPH (Gauss et al. 2013, Kleven et al. 2015). While the N-terminal domain does reduce flavin, contrary to earlier predictions, it does not harbor a high affinity flavin-binding site (Gauss et al. 2013). Instead, the major constituents of the high affinity FAD-binding site are found on the cytosolic face of the transmembrane domain of STEAP3 (Kleven et al. 2015). Because the residues involved in FAD binding in the STEAP3 transmembrane domain are strictly conserved among all Steap family members (Steap1-4), it was concluded that Steap family members in general, including STEAP4, bind flavin primarily through the cytosolic face of the transmembrane domain. This work also strongly suggests that FAD is the preferred flavin for all Steap family members (Kleven et al. 2015), a conclusion that was recently verified for STEAP1 (Kim et al. 2016).

In initial studies, the specific activity of Steap4 for reduction of copper suggested copper might also be a physiologically relevant substrate (Ohgami et al. 2006). Importantly, Gauss and coworkers subsequently determined the affinity of rat Steap4 for iron and copper and found similar $K_{\mathrm{m}}$ values for each of these substrates. Further, the affinity of rat Steap4 for both iron and copper is equal to or greater than those of other characterized mammalian ferric and cupric reductases (Gauss et al. 2013). Kleven and coworkers also identified a conserved $\mathrm{Fe}^{3+}$-binding site on the extracellular face of STEAP3. Again, because these sequence motifs are present in STEAP4 and all other Steap family members, this strongly suggests the presence of a conserved metal-binding site on the extracellular face (or endosome/organelle membrane) of STEAP4 (Kleven et al. 2015). Further, biochemical and structural studies also suggest that STEAP3 and STEAP4 each function as homodimers (Sendamarai et al. 2008, Gauss et al. 2013, Kleven et al. 2015).

Mechanistically, then, the current view is that the Steap4 oxidoreductase domain draws two electrons from cytoplasmic NADPH (oxidizing it to $\mathrm{NADP}^{+}$), passing these to FAD at the cytosolic face of the transmembrane domain, reducing it to $\mathrm{FADH}_{2} . \mathrm{FADH}_{2}$, in turn, passes electrons, one at a time, through the transmembrane heme, to the cell surface metal-binding site where $\mathrm{Fe}^{3+}$ is reduced to $\mathrm{Fe}^{2+}$, or $\mathrm{Cu}^{2+}$ to $\mathrm{Cu}^{1+}$ (Kleven et al. 2015). $\mathrm{Fe}^{2+}$ and $\mathrm{Cu}^{1+}$ are then ready for transport across the membrane by their respective transporters. 


\section{STEAP4 and cellular uptake of iron and copper}

In healthy individuals, there is little extracellular free iron. Most free iron is bound by the $80 \mathrm{kDa}$ protein, transferrin. Transferrin serves to solubilize $\mathrm{Fe}^{3+}$, which would otherwise complex with $\mathrm{OH}^{-}$and precipitate (rust).

To meet their iron needs, erythroid cells in particular are dependent upon the transferrin cycle. In this cycle, iron-loaded transferrin (Tf) binds to the cell surface transferrin receptor (TfR) (Lawrence et al. 1999). The Tf:TfR complex then enters the endosome via receptormediated endocytosis. Within the low-pH endosome, iron is released from Tf and reduced from $\mathrm{Fe}^{+3}$ to $\mathrm{Fe}^{+2}$ by Steap3, permitting transport across the endosomal membrane by divalent metal iron transporter 1 (DMT1), which is selective for $\mathrm{Fe}^{2+}$. The apo-Tf:TfR complex is then recycled to the cell surface, where, at neutral $\mathrm{pH}$, the apo-Tf is released to participate in the cycle once again (Andrews et al. 2015). Other cells with reduced iron needs can, however, take advantage of non-transferrin bound iron. For non-transferrin bound iron, other metal transporters such as Zip8 or Zip14 might also play a role (Zhao et al. 2010, Wang et al. 2012a, Wang \& Knutson 2013, Kleven et al. 2015).

Copper transporter 1 (CTR1) is the major copper transporter involved in cellular copper uptake in mammals (Kaplan \& Lutsenko 2009, Wang et al. 2011, Kidane et al. 2012). Thus, although the specific identity of the iron and copper transporters is not known, overexpression of mouse Steap4 in HEK-293 cells stimulates cellular uptake of these metals. In fact, in this assay, Steap4 shows the highest copper and iron uptake values of any member of the Steap family (Ohgami et al. 2006). This strongly suggests that Steap4 plays a role in the cellular uptake of iron and copper and that STEAP4 may be critical to both iron and copper homeostasis at the cellular level, and within the body in general.

\section{Iron and the innate immune system}

Iron withholding is an important strategy of the innate immune system. Transferrin, for example, serves to sequester $\mathrm{Fe}^{3+}$ from pathogenic invaders, for which iron is often the rate-limiting nutrient. Thus, several proteins involved in iron transport and homeostasis, including hepcidin, ferritin and transferrin are upregulated or downregulated in individuals suffering from chronic infection.

The increased expression of STEAP4 in response to inflammatory cytokines (see below) suggests Steap4 is also linked to inflammation and the innate immune response. Increased expression of cell surface Steap4 might therefore be expected to increase iron and/or copper import into the cell. While this strategy might reduce the concentration of circulating $\mathrm{Fe}^{3+}$ (and $\mathrm{Cu}^{2+}$ ) available to pathogens, it might also be expected to result in increased intracellular $\mathrm{Fe}^{2+}$, which if mishandled could lead to increased oxidative stress. The upregulation of Steap4 and potentially iron import by proinflammatory cytokines suggests, at least at the systemic level, that STEAP4-mediated iron transport into the cell is beneficial, perhaps because it reduces the concentration of circulating iron.

\section{STEAP4 tissue and cellular expression}

One approach to understanding STEAP4's role in metabolic dysfunction begins with determining the tissues and organs in which it is expressed. Reviews of tissue expression patterns showed that STEAP4 is found to varying levels in most organs with the exception of the central nervous system (Gomes et al. 2012, Grunewald et al. 2012). More specifically, analysis of metabolic tissues has revealed that STEAP4 is found in adipose tissue, hepatocytes and pancreatic islets/beta-cells. These tissues are discussed in more detail below.

\section{STEAP4 in adipocytes}

Relative to other cell types, the effects of STEAP4 expression and mis-expression are most studied in adipocytes. STEAP4 expression is higher in mature adipocytes rather than young undifferentiated preadipocytes (Moldes et al. 2001, Chen et al. 2009, Moreno-Navarrete et al. 2011, Narvaez et al. 2013, Sikkeland \& Saatcioglu 2013). Emerging evidence has demonstrated a role for STEAP4 in the cellular response to nutritional and inflammatory signals (Wellen et al. 2007). When overexpressed, STEAP4 has been shown to reduce inflammation and better regulate glucose metabolism in a mouse model of streptozotocininduced diabetes (Chuang et al. 2015). In another study, STEAP4 overexpression shifted macrophage polarization to enhance protection of adipose tissue, leading to reduced insulin resistance in diabetic ApoE-/-/LDLR-/mice (Han et al. 2013).

In contrast, reducing or eliminating STEAP4 negatively impacts adipose tissue. STEAP4 expression has also been implicated in the translocation of glucose transporter 4 (GLUT4) to the cell surface, correlating reduced or abolished STEAP4 with increased insulin resistance

Published by Bioscientifica Ltd 
and the pathophysiology of type 2 diabetes (T2D) (Cheng et al. 2011, Qin et al. 2011). At the whole animal level, Steap4 KO mice are prone to developing obesity, insulin resistance, glucose intolerance (Wellen et al. 2007) and hyperglycemia, hallmarks of metabolic syndrome and T2D. Thus, STEAP4 appears to play a protective role against metabolic and proinflammatory stress in adipocytes and adipose tissue.

\section{STEAP4 expression in hepatocytes}

In hepatocytes, the lack of STEAP4 has been suggested to correlate with dysfunctional responses to fat and nutrient influx and the onset of fatty liver disease (Wellen et al. 2007). On the other hand, expression of STEAP4 in hepatocytes has been suggested to cause a suppression of lipogenesis and gluconeogenesis (Wang et al. 2012b). Overexpression of STEAP4 has been shown to ameliorate steatosis and insulin resistance caused by high-fat diet (Kim et al. 2015). Hepatic STEAP4 overexpression also decreases hepatitis B virus X-protein signaling and subsequent metabolic dysfunction (Kim et al. 2012a). In mice with STEAP4 deficiency, liver size is elevated, hepatic insulin receptor signaling is impaired and rates of fatty liver disease are increased (Wellen et al. 2007). As with adipose tissue, STEAP4 thus appears to play a protective role against metabolic and inflammatory stresses.

\section{STEAP4 in pancreatic islets}

Steap4 is expressed in pancreatic beta-cell lines (Berner et al. 2015) and primary mouse islets (Sharma et al. 2015) and is upregulated by exposure to cytokines or by free fatty acids (Sharma et al. 2015). In human islets, STEAP4 expression is reduced in obesity and hyperglycemia (HbA1c), but elevated in donors with high white blood cell count (Gordon et al. 2017). Islet STEAP4 expression also appears to be slightly higher in women compared to men (Gordon et al. 2017). To date, little is known about the function or localization of STEAP4 in islets and warrants further study.

\section{Cellular localization of STEAP4}

STEAP4 seems to localize specifically to the Golgi apparatus network and the plasma membrane of cells (Korkmaz et al. 2005, Yoo et al. 2014). One study suggests that STEAP4 co-localizes with caveolin-1, which is known to play a role in insulin signaling in adipose tissues
(Chambaut-Guerin \& Pairault 2005). Studies of osteoclasts also suggest that STEAP4 can be found in endosomes important in osteoclast development and function (Zhou et al. 2013). Further, with regard to the subcellular distribution of STEAP4, rat STEAP4 shows ferric and cupric reductase activity at acidic $\mathrm{pH}$ suggesting it also functions within intracellular organelles, particularly endosomes and granules, to reduce these metals (Gauss et al. 2013). As STEAP4 is examined for localization in more cell types, it would be intriguing if the STEAP4 subcellular distribution differed with cell types, i.e., was found in endosomes and/or the plasma membrane of some cell types, but in the Golgi, ER, nuclear membranes or other organelles in other cell types. While purely speculative as this time, this would suggest STEAP4 has tissue-specific actions that may differ by cell type.

\section{Regulatory influences on STEAP4 expression}

With potential roles in metabolism, inflammation, cell growth and cancer, STEAP4 expression is regulated by a number of different factors. Known regulatory factors are described below and summarized in Fig. 2 .

\section{Cytokines}

Studies have suggested STEAP4 plays a fundamental role in cellular homeostasis during inflammatory stress and a key regulator of STEAP4 expression is cytokine exposure. Several reports show that Steap 4 mRNA increases in a dosedependent manner with TNF $\alpha$ exposure, suggesting TNF $\alpha$ accelerates STEAP4 synthesis (Moldes et al. 2001, Chen et al. 2009, Tanaka et al. 2012a,b). Similar to the effect of TNF $\alpha$,

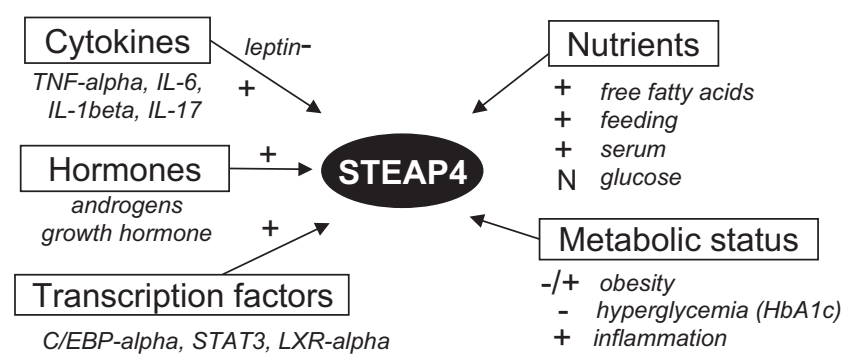

Figure 2

Factors known to regulate STEAP4. ' + ' indicates a factor that upregulates STEAP4 expression; ' - ' indicates a factor that downregulates STEAP4 expression. ' $-/+$ ' indicates both increased STEAP4 or decreased STEAP4 have been observed in obesity. N, no significant effect detected in adipose tissue (Wellen et al. 2007) or pancreatic islets (Sharma et al. 2015); note that high glucose increases STEAP4 expression in mesangial cells (Chuang et al. 2015).
๑ 2017 Society for Endocrinology Printed in Great Britain 
IL-6 exposure also results in an increase in Steap4 mRNA (Fasshauer et al. 2004) and STEAP4 protein levels in human adipocytes (Chen et al. 2010). Moreover, simultaneous exposure to multiple cytokines including IL-1 $\beta$, TNF $\alpha$ and IL-6 stimulates STEAP4 expression in a synergistic manner in adipocytes (Kralisch et al. 2009). Steap4 expression is also increased in hepatocytes when cells are exposed to IL-17 or $\mathrm{TNF} \alpha$, and together, these cytokines produce a synergistic effect (Sparna et al. 2010, Wu et al. 2015). The only cytokine/chemokine found to inhibit STEAP4 expression thus far is leptin (Chen et al. 2010).

\section{Nutrients}

Exposure to nutrients also plays a fundamental role in the regulation of STEAP4. Adipocyte exposure to high serum and fatty acids markedly increases Steap4 expression, whereas glucose and insulin treatment shows no effect on expression (Waki \& Tontonoz 2007, Wellen et al. 2007). Supporting these findings, islet expression of STEAP4 also increased in response to 48-h exposure to free fatty acids but not to high glucose (Sharma et al. 2015). Moreover, Steap4 expression was increased following meals in normal lean mice, but this effect was lost in obese mice (Wellen et al. 2007).

It is not clear, however, whether STEAP4 is elevated or depressed in conditions of obesity resulting from chronic nutrient excess. Initial studies found that STEAP4 levels in adipocytes and white adipose tissue were increased in obesity (Arner etal. 2008, Catalan etal. 2012). Other studies, however, demonstrated that STEAP4 protein and/or gene expression is downregulated in obese patients (Zhang et al. 2008, Moreno-Navarrete et al. 2011, Kim et al. 2015, Ozmen et al. 2016, Xu et al. 2016). Additionally, STEAP4 expression in both fat and muscle was reduced among the most insulin-resistant individuals independent of BMI (Elbein et al. 2011). Further, in human pancreatic islets, reduced STEAP4 gene expression correlates with increased BMI (Gordon et al. 2017) among non-diabetic donors, but not among donors with T2D. Donors with T2D showed reduced STEAP4 gene expression with increased HbA1c, a key indicator of chronic hyperglycemia (Gordon et al. 2017). On balance, these findings suggest that reduced STEAP4 expression is associated with obesity.

\section{Hormones}

In addition to cytokine and nutrient exposure, STEAP4 expression is regulated by hormones such as growth hormone (GH) and testosterone. Maneschi and coworkers established that an increase in testosterone increases STEAP4 expression in visceral adipose tissue (Maneschi et al. 2012). Other research has shown that STEAP4 expression is markedly increased in prostate cancer tissues in which testosterone production is high (Korkmaz et al. 2005). Interestingly, testosterone is important in normal glucose metabolism, insulin signaling and the prevention of metabolic syndrome, and it has been suggested that STEAP4 acts synergistically with testosterone to achieve this effect (Maneschi et al. 2012, Vignozzi et al. 2012). Not surprisingly, an increase in $\mathrm{GH}$, which impacts glucose homeostasis among other effects, has also been shown to increase the expression of STEAP4 in a dose-dependent manner (Fasshauer et al. 2003). Although the exact connection between GH and insulin resistance is unclear, an excess of GH hinders the action of insulin in tissues, which may act as a stressor to promote increased STEAP4 expression to counter the effect of testosterone.

\section{Transcription factors}

At the transcriptional level, STEAP4 expression is driven by several transcription factors and signaling cascades. Recent studies have shown that two factors involved in adipocyte differentiation, CCAAT/enhancer-binding protein $\alpha(\mathrm{C} / \mathrm{EBP} \alpha)$ and liver-X-receptor-alpha activate the STEAP4 promoter, whereas PPAR $\gamma$ does not (Wellen et al. 2007). Other studies have demonstrated that STEAP4 expression is regulated by $\mathrm{C} / \mathrm{EBP} \alpha$ and STAT3 in the liver (Ramadoss et al. 2010). These transcription factors are activated in response to inflammatory and nutritional signals, suggesting that STEAP4 might play a protective role at the cellular or systemic level (Ramadoss et al. 2010). Similarly, in mesangial cells where high glucose induces Steap4 expression, the increased expression was found to be dependent upon S100B, JNK, PI3K, JAK2 and STAT3 (Chuang et al. 2015).

\section{Regulatory and protective influences of STEAP4}

Although STEAP4 functions as a metalloreductase at the molecular level, overexpression of STEAP4 has been shown to modulate the expression of several genes. For example, in the mesangial cells discussed immediately above, STEAP4 overexpression attenuates high glucose http://joe.endocrinology-journals.org DOI: 10.1530/JOE-16-0594 (c) 2017 Society for Endocrinology Printed in Great Britain
Published by Bioscientifica Ltd. 
induced expression of collagen IV, fibronectin and COX2, as well as the expression of TGF- $\beta$, ERK1/2, Akt, Smad2/3 and STAT3 (Chuang et al. 2015). The observation that high glucose induces STAT3-dependent expression of STEAP4 (above), and that overexpression of STEAP4 in turn attenuates expression of STAT3, as well as other important signaling molecules like TGF- $\beta$, ERK1/2, Akt and Smad2/3, suggests STEAP4 may participate in a feedback loop that modulates the effects of high glucose on mesangial cells.

Steap4 is also reported to show protective effects at the systemic level. STEAP4 overexpression reduced rates of atherosclerosis and plaque formation in diabetic mice (Wang et al. 2014), while its deficiency promoted atherosclerosis (Freyhaus et al. 2012). Similarly, STEAP4 overexpression reduced migration of neutrophil-like HL60 (Tanaka et al. 2012a) and reduced IL-6 and IL-8 cytokine expression (Tanaka et al. 2012b), whereas siRNA knockdown of STEAP4 increased cytokine signaling in patients with rheumatoid arthritis (Tanaka et al. 2012b), again consistent with a role for Steap4 in a negative feedback loop. These protective effects have also been observed in adipocytes and hepatocytes as discussed previously.

\section{STEAP4 in metabolic disorders}

\section{Genomewide associations between STEAP4 and metabolic disorders}

A number of genome-wide association studies have identified genetic variants of STEAP4 associated with obesity and obesity-related disorders. For example, metabolic syndrome is known to impair glucose tolerance, insulin sensitivity and other conditions linked with obesity. It was found that individuals with metabolic syndrome showed associations with several single nucleotide polymorphisms (SNPs) within or near the STEAP4 gene (Nanfang et al. 2010, Guo et al. 2011a, Chen et al. 2014), particularly in the Uyghur people of western China who are genetically a mix of east Asian and western European genetic lineages (Yao et al. 2004). STEAP4 variants were also associated with metabolic syndrome among the Han Chinese (Qi et al. 2015). Among western Europeans, an epidemiological study examined constitutive parameters of metabolic syndrome in French Caucasians and found that STEAP4 variants were associated with higher triglyceride levels, fasting glucose and fat intake; however, no relationship between STEAP4 and the prevalence of metabolic syndrome was found (Miot et al. 2010).
Genetic variations in STEAP4 have also been found to impact obesity and insulin secretion. A pair of studies associated a common variant in the STEAP4 gene (rs1981529 Gly75Asp, 224A/G) with obesity in the Uyghur population (Guo et al. 2011b, Han et al. 2012). However, no relationship was found between STEAP4 and severe obesity in a Norwegian cohort (Wangensteen et al. 2011). Finally, an islet-targeted genomewide association study of Hispanic Americans implicated a STEAP4 polymorphism with measures of acute insulin response to glucose (Sharma et al. 2015), suggesting a role for STEAP4 in insulin-secreting beta-cells. In each case, it is not known whether loss-of-function or gain-of-function mutations in STEAP4 are related to disease status in these studies. Collectively, however, these associations suggest a potentially important role for STEAP4 in obesity and related metabolic disorders, and further mechanistic work is clearly needed.

\section{STEAP4, iron and T2D}

Several excellent reviews detail cellular iron regulation and the relationship between iron and diabetes (Swaminathan et al. 2007, Simcox \& McClain 2013, Backe et al. 2016). Further, iron regulation is governed by multiple processes involving heme vs non-heme dietary iron intake, iron absorption, inflammation and cellular iron regulation that are more complex than we can address within the scope of this review. For this reason, our discussion of iron will be largely limited to STEAP4. Critical to this discussion, however, is the understanding that while iron is essential for a variety of reasons (DNA synthesis, electron transport chain and ATP production, etc.), excess iron results in the production of hydroxyl radicals (via Fenton Chemistry) and reactive oxygen species (ROS) in general. In turn, these ROS react indiscriminately with lipids, proteins and DNA, leading to oxidative damage and cellular stress. In short, iron is a double-edged sword that cuts both ways.

Not surprisingly then, long-standing evidence links T2D with numerous conditions of iron overload including hereditary hemochromatosis (Dymock et al. 1972, McClain et al. 2006) and blood transfusions associated with blood disorders such as beta-thalassemia major (Merkel et al. 1988, Dmochowski et al. 1993, Cario et al. 2003). Markers for elevated iron levels are also strongly associated with increased risk of T2D in the general population (Ford \& Cogswell 1999, FernandezReal et al. 2002a) and in gestational diabetes (Lao \& Tam 1997, Rawal et al. 2016). There is evidence that simply

Published by Bioscientifica Ltd 
reducing iron levels by phlebotomy can reduce insulin resistance, improve insulin secretion and lower blood glucose in patients with T2D (Facchini 1998, FernandezReal et al. 2002b).

Studies have shown that iron overload can cause insulin resistance in adipocytes (Dongiovanni et al. 2013, Wlazlo et al. 2013, Gao et al. 2015), impair hepatocytes (Ramm \& Ruddell 2005, Fargion et al. 2011) and cause beta-cell dysfunction (Cooksey et al. 2004). In contrast, when DMT1 was knocked out in beta-cells, the result was iron depletion and subsequent reductions in ROS, mitochondrial activity and insulin secretion (Hansen et al. 2012). Consistent with this, under conditions of increased inflammatory stress, DMT1 deficiency was found to protect beta-cells from dysfunction and apoptosis (Hansen et al. 2012). These studies suggest that excessive iron uptake and the resulting oxidative stress inhibit normal beta-cell function, whereas inhibition of iron uptake is protective under conditions of inflammatory stress.

To date, a single report links STEAP4 with changes in iron regulation associated with metabolic disorders. STEAP4 and lipocalin-2 (aka NGAL, which sequesters bacterial siderophores) were both negatively correlated with serum iron levels and positively correlated with markers of inflammation in obese individuals (Catalan et al. 2012). These findings suggest that increased STEAP4 expression from low-grade inflammation in obesity could drive down circulating free iron levels and presumably drive up cellular iron accumulation. Considering the detrimental effect of iron overload and STEAP4's role in iron transport, it could be argued that knocking out STEAP4 might be beneficial under conditions of stress by reducing iron accumulation and reducing ROS production as occurs for DMT1. However, the opposite appears to be true; STEAP4 deficiency leads to dysfunction in several tissues including liver hepatocytes and adipocytes and exacerbates inflammatory environments. How changes in STEAP4 expression or activity would impact cellular function in these metabolic tissues, particularly in conditions of iron overload, acute vs chronic inflammation, or nutrientassociated stress, is yet another open question warranting future study.

\section{STEAP4, copper and type-2 diabetes}

Copper is also important for many biological functions. Copper is necessary for the activity of superoxide dismutase, an important antioxidant enzyme that scavenges the free radical superoxide (McCord \& Fridovich 1969). Beta-cells are thought to be especially susceptible to oxidative stress because of very low antioxidant enzyme activity (Karunakaran \& Park 2013). Thus, copper import by Steap 4 may facilitate increased activity of cytosolic superoxide dismutase, protecting the cell against oxidative stress.

Copper is also a cofactor for cytochrome c oxidase and is thus critical for mitochondrial electron transport and ATP synthesis (Kim et al. 2012b, Xu et al. 2013). Cytochrome c oxidase activity is thus reduced in copperdeficient cells, which could lead to mitochondrial dysfunction. Supporting this idea, increasing dietary copper in Cohen diabetic rats restored insulin secretion and improved glycemia by increasing respiratorychain enzyme cytochrome c oxidase (WekslerZangen et al. 2013).

However, a classic study of biological metals in humans links elevated levels of circulating copper with T2D (Walter et al. 1991), and a recent systematic review also concludes increased copper is associated with both type 1 and type 2 diabetes (Qiu et al. 2016). In addition, when diabetic $(\mathrm{db} / \mathrm{db})$ mice with elevated copper levels were given a copper chelator, the mice showed reduced copper and ROS levels and improved glucose tolerance (Tanaka et al. 2009). Thus, the evidence appears to favor a link between increased circulating copper and diabetes, but the mechanism for this link is not well understood.

To date, there has been little study of STEAP4 with respect to copper homeostasis. Evidence of a role for STEAP4 in copper transport comes from (i) the demonstration of Steap4 reduction of $\mathrm{Cu}^{2+}$ to $\mathrm{Cu}^{+}$with a $\mathrm{Cu}^{+}-$sensitive chelating dye (Ohgami et al. 2006), (ii) measurements of cellular copper uptake utilizing transiently transfected HEK-293T cells with STEAP4 expression plasmids (Ohgami et al. 2006) and (iii) the subsequent determination of a high affinity (physiologically relevant, low $K_{\mathrm{m}}$ ) for copper (Gauss et al. 2013). In this regard, we point out that increased intracellular copper levels and reduced circulating levels are not mutually exclusive, as STEAP4-mediated transport of circulating copper into the cell would explain both observations. This might also contribute to a functional electron transport chain, or the reduction in ROS in cells expressing STEAP4. Future studies will hopefully precisely pinpoint the links between STEAP4, copper homeostasis and metabolic disorders.

\section{Interacting partners for STEAP4}

While the ferric reductase activity of Steap4 can explain a number of observations related to over, under or misexpression of STEAP4, it is difficult to rationalize the

Published by Bioscientifica Ltd. 
reported protective effects of STEAP4 with potentially increased iron import and production of ROS. This suggests Steap4 might possess metal-independent actions, and that understanding these actions will be important in reconciling these apparently contradictory observations. In this light, the literature suggests that STEAP proteins in general, and Steap4 in particular, may be involved in protein-protein interactions that modulate STEAP activity, or the activities of the interacting partners. For example, STEAP3 has been reported to interact with NIX and MYT1 kinase, localizing these proteins at the plasma membrane, and suggesting a role in apoptosis or cell cycle control. STEAP3 is also reported to interact with translationally controlled tumor protein (Amzallag et al. 2004), and there is strong genetic evidence for an interaction between STEAP3 and TfR (Jabara et al. 2016). Importantly, Steap3 can also form a heterodimer with STEAP4 (Kleven 2015). Increased STEAP4 expression could then conceivably modulate the activity of STEAP3 and the activities or subcellular locations of proteins interacting with STEAP3 (NIX, MYT1), thus potentially impacting metal homeostasis, apoptosis and cell cycle control.

Similarly, Steap4 has also been reported to interact with BNIP3L (Passer et al. 2003), focal adhesion kinase-1 (Tamura \& Chiba 2009) and S100B (Chuang et al. 2015), again suggesting possible links to apoptosis, differentiation and cell cycle progression. In addition, STEAP4 is a reported target of the rhomboid protease RHBDL4/RHBDD1 (Wan et al. 2012). Finally, large-scale interactome studies and their related data bases (BioGrid, IntAct, STRING, etc.) provide an expanded list of potential interactions that might help explain the protective effects. Importantly, most of these potential interactions have not been characterized with respect to metalloreductase activity, metal import and the protective effects of STEAP4, and much additional work is clearly needed. However, one possible explanation for the protective activity of Steap4 is that it localizes one or more of these interacting partners to the membrane, thus modulating the activity of the respective signaling pathway, completing a regulatory feedback loop.

\section{STEAP4 in cancer}

In addition to its role in cellular or systemic homeostasis in the presence of inflammatory stress, STEAP4 is also associated with tumorigenesis. STEAP4 overexpression has been suggested to increase ROS, which may contribute to increased mutational rates and further prostate cancer progression (Jin et al. 2015). At the same time, elevated levels of STEAP4 in prostate cancer cells might also help meet the increased need for iron in rapidly multiplying cells, signifying its role in cell growth and maintenance (Korkmaz et al. 2005). Thus, while STEAP4 may have a beneficial role in protection from inflammatory stress in a host of chronic metabolic and inflammatory diseases (Tamura \& Chiba 2009, Lindstad et al. 2010, 2016, Gomes et al. 2012, Grunewald et al. 2012, Jin et al. 2015, $\mathrm{Wu}$ et al. 2015), its mis-expression may also promote cancer cell proliferation and cancer progression, adding to the complexity in understanding the role of STEAP4 in health and disease.

\section{Conclusion}

STEAP4 has emerged as a key player in inflammatory responses in metabolic tissues and in cellular iron and copper homeostasis. It is well established that iron and copper, among other trace metals, are essential to maintaining many cellular processes. Numerous studies have pointed to iron overload (Swaminathan et al. 2007, Simcox \& McClain 2013, Backe et al. 2016) and copper overload (Walter et al. 1991, Tanaka et al. 2009, Qiu et al. 2016) as contributing factors to insulin resistance and beta-cell dysfunction. With such obvious links, it is somewhat surprising that STEAP4's function as a metalloreductase has not been examined in the context of metabolic diseases. Several other iron-regulating genes have been recognized as important to both inflammation and metabolic disorders including lipocalin-2 (Wang et al. 2007), hepcidin and ferritin (Andrews et al. 2015). It has yet to be determined whether STEAP4's protective effects against metabolic and inflammatory damage are mediated by iron regulation, copper regulation, immunomodulation, by some combination of these or by some completely novel mechanism. Given the clear links between STEAP4 and numerous metabolic disorders, defining these putative functions of STEAP4 is a goal worthy of future discovery and discussion.

\section{Plain language summary}

Problems with the cellular regulation of iron and copper have long been associated with diseases of metabolism, including type 2 diabetes. In this review, we examine a protein involved with iron and copper handling in cells called STEAP4 and its connections to inflammation and diseases of obesity.

Published by Bioscientifica Ltd. 


\section{Declaration of interest}

The authors declare that there is no conflict of interest that could be perceived as prejudicing the impartiality of this review.

\section{Funding}

This work was supported by the National Institutes of Health R01 DK089182 to C S N, the Osteopathic Heritage Foundation and the Heritage College of Osteopathic Medicine at Ohio University.

\section{Author contribution statement}

R T S, C M L, H M G and C S N all contributed to research and writing this manuscript.

\section{Acknowledgments}

The authors thank the Research and Scholarly Advancement Fellowship (RSAF) program at Ohio University for providing R T S the opportunity to participate in the project.

\section{References}

Amzallag N, Passer BJ, Allanic D, Segura E, Thery C, Goud B, Amson R $\&$ Telerman A 2004 TSAP6 facilitates the secretion of translationally controlled tumor protein/histamine-releasing factor via a nonclassical pathway. Journal of Biological Chemistry 279 46104-46112. (doi:10.1074/jbc.M404850200)

Andrews M, Soto N \& Arredondo-Olguin M 2015 Association between ferritin and hepcidin levels and inflammatory status in patients with type 2 diabetes mellitus and obesity. Nutrition 31 51-57. (doi:10.1016/j.nut.2014.04.019)

Arner P, Stenson BM, Dungner E, Naslund E, Hoffstedt J, Ryden M \& Dahlman I 2008 Expression of six transmembrane protein of prostate 2 in human adipose tissue associates with adiposity and insulin resistance. Journal of Clinical Endocrinology and Metabolism 93 2249-2254. (doi:10.1210/jc.2008-0206)

Backe MB, Moen IW, Ellervik C, Hansen JB \& Mandrup-Poulsen T 2016 Iron regulation of pancreatic beta-cell functions and oxidative stress. Annual Review of Nutrition 36 241-273. (doi:10.1146/annurevnutr-071715-050939)

Berner A, Bachmann M, Bender C, Pfeilschifter J, Christen U \& Muhl H 2015 Though active on RINm5F insulinoma cells and cultured pancreatic islets, recombinant IL-22 fails to modulate cytotoxicity and disease in a protocol of streptozotocin-induced experimental diabetes. Frontiers in Pharmacology 6 317. (doi:10.3389/fphar.2015.00317)

Cario H, Holl RW, Debatin K-MM \& Kohne E 2003 Insulin sensitivity and beta-cell secretion in thalassaemia major with secondary haemochromatosis: assessment by oral glucose tolerance test. European Journal of Pediatrics 162 139-146. (doi:10.1007/s00431-002-1121-7)

Catalan V, Gomez-Ambrosi J, Rodriguez A, Ramirez B, Rotellar F, Valenti V, Silva C, Gil MJ, Salvador J \& Fruhbeck G 2012 Six-transmembrane epithelial antigen of prostate 4 and neutrophil gelatinase-associated lipocalin expression in visceral adipose tissue is related to iron status and inflammation in human obesity. European Journal of Nutrition $\mathbf{5 2}$ 1587-1595. (doi:10.1007/s00394-012-0464-8)

Chambaut-Guerin AM \& Pairault J 2005 Tumour necrosis factor alphainduced adipose-related protein (TIARP): co-localization with caveolin-1. Biology of the Cell 97 339-347. (doi:10.1042/BC20040062)

http://joe.endocrinology-journals.org

DOI: $10.1530 / \mathrm{JOE}-16-0594$
() 2017 Society for Endocrinology Printed in Great Britain
Chen XH, Zhao YP, Zhu C, Ji CB, Zhang CM, Zhu JG, Gao CL \& Guo XR 2009 Regulative role of TNFalpha on STEAP4 gene in matured human adipocytes. Chinese Journal of Contemporary Pediatrics 11 1008-1011.

Chen X, Zhu C, Ji C, Zhao Y, Zhang C, Chen F, Gao C, Zhu J, Qian L \& Guo X 2010 STEAP4, a gene associated with insulin sensitivity, is regulated by several adipokines in human adipocytes. International Journal of Molecular Medicine 25 361-367. (doi:10.3892/ ijmm_00000353)

Chen X, Huang Z, Zhou B, Wang H, Jia G, Liu G \& Zhao H 2014 STEAP4 and insulin resistance. Endocrine 47 372-379. (doi:10.1007/s12020014-0230-1)

Cheng R, Qiu J, Zhou XY, Chen XH, Zhu C, Qin DN, Wang JW, Ni YH, Ji CB \& Guo XR 2011 Knockdown of STEAP4 inhibits insulin-stimulated glucose transport and GLUT4 translocation via attenuated phosphorylation of Akt, independent of the effects of EEA1. Molecular Medicine Reports 4 519-523. (doi:10.3892/ mmr.2011.443

Chuang C-T, Guh J-Y, Lu C-Y, Wang Y-T, Chen H-C \& Chuang L-Y 2015 Steap4 attenuates high glucose and S100B-induced effects in mesangial cells. Journal of Cellular and Molecular Medicine 19 1234-1244. (doi:10.1111/jcmm.12472)

Cooksey RC, Jouihan HA, Ajioka RS, Hazel MW, Jones DL, Kushner JP \& McClain DA 2004 Oxidative stress, beta-cell apoptosis, and decreased insulin secretory capacity in mouse models of hemochromatosis. Endocrinology 145 5305-5312. (doi:10.1210/en.2004-0392)

Dmochowski K, Finegood DT, Francombe W, Tyler B \& Zinman B 1993 Factors determining glucose tolerance in patients with thalassemia major. Journal of Clinical Endocrinology and Metabolism 77 478-483. (doi:10.1210/jcem.77.2.8345055)

Dongiovanni P, Ruscica M, Rametta R, Recalcati S, Steffani L, Gatti S, Girelli D, Cairo G, Magni P, Fargion S, et al. 2013 Dietary iron overload induces visceral adipose tissue insulin resistance. American Journal of Pathology 182 2254-2263. (doi:10.1016/j. ajpath.2013.02.019)

Dymock IW, Cassar J, Pyke DA, Oakley WG \& Williams R 1972 Observations on the pathogenesis, complications and treatment of diabetes in 115 cases of haemochromatosis. American Journal of Medicine 52 203-210. (doi:10.1016/0002-9343(72)90070-8)

Elbein SC, Kern PA, Rasouli N, Yao-Borengasser A, Sharma NK \& Das SK 2011 Global gene expression profiles of subcutaneous adipose and muscle from glucose-tolerant, insulin-sensitive, and insulin-resistant individuals matched for BMI. Diabetes 60 1019-1029. (doi:10.2337/ db10-1270)

Facchini FS 1998 Effect of phlebotomy on plasma glucose and insulin concentrations. Diabetes Care 21 2190. (doi:10.2337/ diacare.21.12.2190a)

Fargion S, Valenti L \& Fracanzani AL 2011 Beyond hereditary hemochromatosis: new insights into the relationship between iron overload and chronic liver diseases. Digestive and Liver Disease $\mathbf{4 3}$ 89-95. (doi:10.1016/j.dld.2010.07.006)

Fasshauer M, Klein J, Krahlisch S, Lossner U, Klier M, Bluher M \& Paschke R $2003 \mathrm{GH}$ is a positive regulator of tumor necrosis factor alphainduced adipose related protein in 3T3-L1 adipocytes. Journal of Endocrinology 178 523-531. (doi:10.1677/joe.0.1780523)

Fasshauer M, Kralisch S, Klier M, Lossner U, Bluher M, Chambaut-Guerin AM, Klein J \& Paschke R 2004 Interleukin-6 is a positive regulator of tumor necrosis factor alpha-induced adipose-related protein in 3T3-L1 adipocytes. FEBS Letters 560 153-157. (doi:10.1016/S00145793(04)00096-1)

Fernandez-Real JM, Lopez-Bermejo A \& Ricart W 2002a Cross-talk between iron metabolism and diabetes. Diabetes 51 2348-2354. (doi:10.2337/diabetes.51.8.2348)

Fernandez-Real JM, Penarroja G, Castro A, Garcia-Bragado F, HernandezAguado I \& Ricart W $2002 b$ Blood letting in high-ferritin type 2 diabetes: effects on insulin sensitivity and beta-cell function. Diabetes 51 1000-1004. (doi:10.2337/diabetes.51.4.1000) 
Ford ES \& Cogswell ME 1999 Diabetes and serum ferritin concentration among U.S. adults. Diabetes Care 22 1978-1983. (doi:10.2337/ diacare.22.12.1978)

Gao Y, Li Z, Gabrielsen JS, Simcox JA, Lee S, Jones D, Cooksey B, Stoddard G, Cefalu WT \& McClain DA 2015 Adipocyte iron regulates leptin and food intake. Journal of Clinical Investigation 125 3681-3691. (doi:10.1172/JCI81860)

Gauss GH, Kleven MD, Sendamarai AK, Fleming MD \& Lawrence CM 2013 The crystal structure of six-transmembrane epithelial antigen of the prostate 4 (Steap4), a ferri/cuprireductase, suggests a novel interdomain flavin-binding site. Journal of Biological Chemistry $\mathbf{2 8 8}$ 20668-20682. (doi:10.1074/jbc.M113.479154)

Gomes IM, Maia CJ \& Santos CR 2012 STEAP proteins: from structure to applications in cancer therapy. Molecular Cancer Research 10 573-587. (doi:10.1158/1541-7786.MCR-11-0281)

Gordon HM, Majithia N, MacDonald PE, Fox JEM, Sharma PR, Byrne FL, Hoehn KL, Evans-Molina C, Langman L, Brayman KL, et al. 2017 STEAP4 expression in human islets is associated with differences in body mass index, sex, HbA1c, and inflammation. Endocrine $\mathbf{5 6}$ 528-537. (doi:10.1007/s12020-017-1297-2)

Grunewald TG, Bach H, Cossarizza A \& Matsumoto I 2012 The STEAP protein family: versatile oxidoreductases and targets for cancer immunotherapy with overlapping and distinct cellular functions. Biology of the Cell. 104 641-657. (doi:10.1111/boc.201200027)

Guo YY, Li NF, Wang CM, Yan ZT, Zhang JH, Wang HM, Zhou L \& Luo WL 2011 $a$ Genetic variation and association of STEAP4 gene with metabolic syndrome in Chinese Uygur patients. Chinese Journal of Medical Genetics 28 78-82. (doi:10.3760/cma.j.i ssn.1003-9406.2011.01.018)

Guo YY, Li NF, Zhou L, Yao XG, Wang HM, Zhang JH \& Luo WL $2011 b$ A common variation within the STEAP4 gene exons is associated with obesity in Uygur general population. Chinese Medical Journal 124 2096-2100.

Han RM, Li NF, Yan ZT, Guo YY, Zhang JH, Wang HM, Hong J \& Zhou L 2012 Genetic polymorphism of six transmembrance protein of prostate 2 associated with diabetes mellitus in Xinjiang Uygur population. Acta Academiae Medicinae Sinicae 34 509-514. (doi:10.3881/j.issn.1000-503X.2012.05.013)

Han L, Tang MX, Ti Y, Wang ZH, Wang J, Ding WY, Wang H, Zhang Y, Zhang W \& Zhong M 2013 Overexpressing STAMP2 improves insulin resistance in diabetic ApoE(-/-)/LDLR(-/-) mice via macrophage polarization shift in adipose tissues. PLOS ONE $\mathbf{8}$ e78903. (doi:10.1371/journal.pone.0078903)

Hansen JB, Tonnesen MF, Madsen AN, Hagedorn PH, Friberg J, Grunnet LG, Heller RS, Nielsen AO, Storling J, Baeyens L, et al. 2012 Divalent metal transporter 1 regulates iron-mediated ROS and pancreatic beta cell fate in response to cytokines. Cell Metabolism 16 449-461. (doi:10.1016/j.cmet.2012.09.001)

Jabara HH, Boyden SE, Chou J, Ramesh N, Massaad MJ, Benson H, Bainter W, Fraulino D, Rahimov F, Sieff C, et al. 2016 A missense mutation in TFRC, encoding transferrin receptor 1 , causes combined immunodeficiency. Nature Genetics 48 74-78. (doi:10.1038/ng.3465)

Jin Y, Wang L, Qu S, Sheng X, Kristian A, Maelandsmo GM, Pallmann N, Yuca E, Tekedereli I, Gorgulu K, et al. 2015 STAMP2 increases oxidative stress and is critical for prostate cancer. EMBO Molecular Medicine 7 315-331. (doi:10.15252/emmm.201404181)

Kaplan JH \& Lutsenko S 2009 Copper transport in mammalian cells: special care for a metal with special needs. Journal of Biological Chemistry 284 25461-25465. (doi:10.1074/jbc.R109.031286)

Karunakaran U \& Park KG 2013 A systematic review of oxidative stress and safety of antioxidants in diabetes: focus on islets and their defense. Diabetes and Metabolism Journal 37 106-112. (doi:10.4093/ dmj.2013.37.2.106)

Kidane TZ, Farhad R, Lee KJ, Santos A, Russo E \& Linder MC 2012 Uptake of copper from plasma proteins in cells where expression of CTR1 has been modulated. Biometals 25 697-709. (doi:10.1007/s10534-0129528-8)

Kim HY, Cho HK, Yoo SK \& Cheong JH 2012a Hepatic STAMP2 decreases hepatitis B virus $\mathrm{X}$ protein-associated metabolic deregulation. Experimental and Molecular Medicine 44 622-632. (doi:10.3858/ emm.2012.44.10.071

Kim HJ, Khalimonchuk O, Smith PM \& Winge DR 2012b Structure, function, and assembly of heme centers in mitochondrial respiratory complexes. Biochimica et Biophysica Acta 1823 1604-1616. (doi:10.1016/j.bbamcr.2012.04.008)

Kim HY, Park SY, Lee MH, Rho JH, Oh YJ, Jung HU, Yoo SH, Jeong NY, Lee HJ, Suh S, et al. 2015 Hepatic STAMP2 alleviates high fat diet-induced hepatic steatosis and insulin resistance. Journal of Hepatology 63 477-485. (doi:10.1016/j.jhep.2015.01.025)

Kim K, Mitra S, Wu G, Berka V, Song J, Yu Y, Poget S, Wang DN, Tsai AL \& Zhou M 2016 Six-transmembrane epithelial antigen of prostate 1 (STEAP1) has a single B heme and is capable of reducing metal ion complexes and oxygen. Biochemistry 55 6673-6684. (doi:10.1021/acs. biochem.7b00209)

Kleven MD 2015 Biochemical characterization of the six-transmembrane epithelial antigen of the prostate family of metalloreductases. PhD Dissertation (3708774). Montana State University, Bozeman, Montana, USA.

Kleven MD, Dlakic M \& Lawrence CM 2015 Characterization of a single b-type heme, FAD, and metal binding sites in the transmembrane domain of six-transmembrane epithelial antigen of the prostate (STEAP) family proteins. Journal of Biological Chemistry 290 22558-22569. (doi:10.1074/jbc.M115.664565)

Korkmaz CG, Korkmaz KS, Kurys P, Elbi C, Wang L, Klokk TI, Hammarstrom C, Troen G, Svindland A, Hager GL, et al. 2005 Molecular cloning and characterization of STAMP2, an androgenregulated six transmembrane protein that is overexpressed in prostate cancer. Oncogene 24 4934-4945. (doi:10.1038/sj.onc.1208677)

Kralisch S, Sommer G, Weise S, Lipfert J, Lossner U, Kamprad M, Schrock K, Bluher M, Stumvoll M \& Fasshauer M 2009 Interleukin1beta is a positive regulator of TIARP/STAMP2 gene and protein expression in adipocytes in vitro. FEBS Letters 583 1196-1200. (doi:10.1016/j.febslet.2009.03.015)

Lao TT \& Tam KF 1997 Maternal serum ferritin and gestational impaired glucose tolerance. Diabetes Care 20 1368-1369. (doi:10.2337/ diacare.20.9.1368)

Lawrence CM, Ray S, Babyonyshev M, Galluser R, Borhani DW \& Harrison SC 1999 Crystal structure of the ectodomain of human transferrin receptor. Science 286 779-782.

Lindstad T, Jin Y, Wang L, Qu S \& Saatcioglu F 2010 STAMPs at the crossroads of cancer and nutrition. Nutrition and Cancer 62 891-895. (doi:10.1080/01635581.2010.509836)

Lindstad T, Qu S, Sikkeland J, Jin Y, Kristian A, Maelandsmo GM, Collas P \& Saatcioglu F 2016 STAMP2 is required for human adipose-derived stem cell differentiation and adipocyte-facilitated prostate cancer growth in vivo. Oncotarget. (doi:10.18632/oncotarget.11131)

Maneschi E, Morelli A, Filippi S, Cellai I, Comeglio P, Mazzanti B, Mello T, Calcagno A, Sarchielli E, Vignozzi L, et al. 2012 Testosterone treatment improves metabolic syndrome-induced adipose tissue derangements. Journal of Endocrinology 215 347-362. (doi:10.1530/ JOE-12-0333)

McClain DA, Abraham D, Rogers J, Brady R, Gault P, Ajioka R \& Kushner JP 2006 High prevalence of abnormal glucose homeostasis secondary to decreased insulin secretion in individuals with hereditary haemochromatosis. Diabetologia 49 1661-1669. (doi:10.1007/s00125006-0200-0)

McCord JM \& Fridovich I 1969 Superoxide dismutase. An enzymic function for erythrocuprein (hemocuprein). Journal of Biological Chemistry 244 6049-6055.

Merkel PA, Simonson DC, Amiel SA, Plewe G, Sherwin RS, Pearson HA \& Tamborlane WV 1988 Insulin resistance and hyperinsulinemia 
in patients with thalassemia major treated by hypertransfusion. New England Journal of Medicine 318 809-814. (doi:10.1056/ NEJM198803313181303)

Miot A, Maimaitiming S, Emery N, Bellili N, Roussel R, Tichet J, Velho G, Balkau B, Marre M, Fumeron F, et al. 2010 Genetic variability at the six transmembrane protein of prostate 2 locus and the metabolic syndrome: the data from an epidemiological study on the Insulin Resistance Syndrome (DESIR) study. Journal of Clinical Endocrinology and Metabolism 95 2942-2947. (doi:10.1210/jc.2010-0026)

Moldes M, Lasnier F, Gauthereau X, Klein C, Pairault J, Feve B \& Chambaut-Guerin AM 2001 Tumor necrosis factor-alpha-induced adipose-related protein (TIARP), a cell-surface protein that is highly induced by tumor necrosis factor-alpha and adipose conversion. Journal of Biological Chemistry 276 33938-33946. (doi:10.1074/ jbc.M105726200)

Moreno-Navarrete JM, Ortega F, Serrano M, Perez-Perez R, Sabater M, Ricart W, Tinahones F, Peral B \& Fernandez-Real JM 2011 Decreased STAMP2 expression in association with visceral adipose tissue dysfunction. Journal of Clinical Endocrinology and Metabolism 96 E1816-E1825. (doi:10.1210/jc.2011-0310)

Nanfang L, Yanying G, Hongmei W, Zhitao Y, Juhong Z, Ling Z \& Wenli L 2010 Variations of six transmembrane epithelial antigen of prostate 4 (STEAP4) gene are associated with metabolic syndrome in a female Uygur general population. Archives of Medical Research 41 449-456. (doi:10.1016/j.arcmed.2010.08.006)

Narvaez CJ, Simmons KM, Brunton J, Salinero A, Chittur SV \& Welsh JE 2013 Induction of STEAP4 correlates with 1,25-dihydroxyvitamin D3 stimulation of adipogenesis in mesenchymal progenitor cells derived from human adipose tissue. Journal of Cellular Physiology 228 2024-2036. (doi:10.1002/jcp.24371)

Ohgami RS, Campagna DR, Greer EL, Antiochos B, McDonald A, Chen J, Sharp JJ, Fujiwara Y, Barker JE \& Fleming MD 2005 Identification of a ferrireductase required for efficient transferrin-dependent iron uptake in erythroid cells. Nature Genetics 37 1264-1269. (doi:10.1038/ ng1658)

Ohgami RS, Campagna DR, McDonald A \& Fleming MD 2006 The Steap proteins are metalloreductases. Blood 108 1388-1394. (doi:10.1182/ blood-2006-02-003681)

Ozmen F, Ozmen MM, Gelecek S, Bilgic I, Moran M \& Sahin TT 2016 STEAP4 and HIF-1alpha gene expressions in visceral and subcutaneous adipose tissue of the morbidly obese patients. Molecular Immunology 73 53-59. (doi:10.1016/j.molimm.2016.03.008)

Passer BJ, Nancy-Portebois V, Amzallag N, Prieur S, Cans C, Roborel de Climens A, Fiucci G, Bouvard V, Tuynder M, Susini L, et al. 2003 The p53-inducible TSAP6 gene product regulates apoptosis and the cell cycle and interacts with Nix and the Myt1 kinase. PNAS 100 2284-2289. (doi:10.1073/pnas.0530298100)

Qi Y, Yu Y, Wu Y, Wang S, Yu Q, Shi J, Xu Z, Zhang Q, Fu Y, Fu Y, et al. 2015 Genetic variants in six-transmembrane epithelial antigen of prostate 4 increase risk of developing metabolic syndrome in a Han Chinese population. Genetic Testing and Molecular Biomarkers 19 666-672. (doi:10.1089/gtmb.2015.0104)

Qin DN, Zhu JG, Ji CB, Chunmei-Shi, Kou CZ, Zhu GZ, Zhang CM, Wang YP, Ni YH \& Guo XR 2011 Monoclonal antibody to six transmembrane epithelial antigen of prostate- 4 influences insulin sensitivity by attenuating phosphorylation of P13K (P85) and Akt: possible mitochondrial mechanism. Journal of Bioenergetics and Biomembranes 43 247-255. (doi:10.1007/s10863-011-9360-9)

Qiu Q, Zhang F, Zhu W, Wu J \& Liang M 2016 Copper in diabetes mellitus: a meta-analysis and systematic review of plasma and serum studies. Biological Trace Element Research 177 53-63. (doi:10.1007/ s12011-016-0877-y)

Ramadoss P, Chiappini F, Bilban M \& Hollenberg AN 2010 Regulation of hepatic six transmembrane epithelial antigen of prostate 4 (STEAP4) expression by STAT3 and CCAAT/enhancer-binding protein alpha.
Journal of Biological Chemistry 285 16453-16466. (doi:10.1074/ jbc.M109.066936)

Ramm GA \& Ruddell RG 2005 Hepatotoxicity of iron overload: mechanisms of iron-induced hepatic fibrogenesis. Seminars in Liver Disease 25 433-449. (doi:10.1055/s-2005-923315)

Rawal S, Hinkle SN, Bao W, Zhu Y, Grewal J, Albert PS, Weir NL, Tsai MY $\&$ Zhang C 2016 A longitudinal study of iron status during pregnancy and the risk of gestational diabetes: findings from a prospective, multiracial cohort. Diabetologia 60 249-257. (doi:10.1007/s00125016-4149-3)

Sendamarai AK, Ohgami RS, Fleming MD \& Lawrence CM 2008 Structure of the membrane proximal oxidoreductase domain of human Steap3, the dominant ferrireductase of the erythroid transferrin cycle. PNAS 105 7410-7415. (doi:10.1073/pnas.0801318105)

Sharma PR, Mackey AJ, Dejene EA, Ramadan JW, Langefeld CD, Palmer ND, Taylor KD, Wagenknecht LE, Watanabe RM, Rich SS, et al. 2015 An islet-targeted genome-wide association scan identifies novel genes implicated in cytokine-mediated islet stress in type 2 diabetes. Endocrinology 156 3147-3156. (doi:10.1210/en.2015-1203)

Sikkeland J \& Saatcioglu F 2013 Differential expression and function of stamp family proteins in adipocyte differentiation. PLOS ONE $\mathbf{8}$ e68249. (doi:10.1371/journal.pone.0068249)

Simcox JA \& McClain DA 2013 Iron and diabetes risk. Cell Metabolism 17 329-341. (doi:10.1016/j.cmet.2013.02.007)

Sparna T, Retey J, Schmich K, Albrecht U, Naumann K, Gretz N, Fischer HP, Bode JG \& Merfort I 2010 Genome-wide comparison between IL-17 and combined TNF-alpha/IL-17 induced genes in primary murine hepatocytes. BMC Genomics 11 226. (doi:10.1186/1471-216411-226)

Swaminathan S, Fonseca VA, Alam MG \& Shah SV 2007 The role of iron in diabetes and its complications. Diabetes Care 30 1926-1933. (doi:10.2337/dc06-2625)

Tamura T \& Chiba J 2009 STEAP4 regulates focal adhesion kinase activation and CpG motifs within STEAP4 promoter region are frequently methylated in DU145, human androgen-independent prostate cancer cells. International Journal of Molecular Medicine $\mathbf{2 4}$ 599-604. (doi:10.3892/ijmm_00000270)

Tanaka A, Kaneto H, Miyatsuka T, Yamamoto K, Yoshiuchi K, Yamasaki Y, Shimomura I, Matsuoka T-A \& Matsuhisa M 2009 Role of copper ion in the pathogenesis of type 2 diabetes. Endocrine Journal 56 699-706. (doi:10.1507/endocrj.K09E-051)

Tanaka Y, Matsumoto I, Iwanami K, Inoue A, Umeda N, Tanaka Y, Sugihara M, Hayashi T, Ito S \& Sumida T 2012a Six-transmembrane epithelial antigen of prostate 4 (STEAP4) is expressed on monocytes/ neutrophils, and is regulated by TNF antagonist in patients with rheumatoid arthritis. Clinical and Experimental Rheumatology 30 99-102.

Tanaka Y, Matsumoto I, Iwanami K, Inoue A, Minami R, Umeda N, Kanamori A, Ochiai N, Miyazawa K, Sugihara M, et al. 2012b Sixtransmembrane epithelial antigen of prostate4 (STEAP4) is a tumor necrosis factor alpha-induced protein that regulates IL-6, IL-8, and cell proliferation in synovium from patients with rheumatoid arthritis. Modern Rheumatology 22 128-136. (doi:10.1007/s10165-011-0475-y)

ten Freyhaus H, Calay ES, Yalcin A, Vallerie SN, Yang L, Calay ZZ, Saatcioglu F \& Hotamisligil GS 2012 Stamp2 controls macrophage inflammation through nicotinamide adenine dinucleotide phosphate homeostasis and protects against atherosclerosis. Cell Metabolism 16 81-89. (doi:10.1016/j.cmet.2012.05.009)

Vignozzi L, Morelli A, Sarchielli E, Comeglio P, Filippi S, Cellai I, Maneschi E, Serni S, Gacci M, Carini M, et al. 2012 Testosterone protects from metabolic syndrome-associated prostate inflammation: an experimental study in rabbit. Journal of Endocrinology 212 71-84. (doi:10.1530/JOE-11-0289)

Waki H \& Tontonoz P 2007 STAMPing out inflammation. Cell 129 451-452. (doi:10.1016/j.cell.2007.04.022) http://joe.endocrinology-journals.org

DOI: $10.1530 / J O E-16-0594$
() 2017 Society for Endocrinology Printed in Great Britain 
Walter RMJ, Uriu-Hare JY, Olin KL, Oster MH, Anawalt BD, Critchfield JW \& Keen CL 1991 Copper, zinc, manganese, and magnesium status and complications of diabetes mellitus. Diabetes Care 14 1050-1056. (doi:10.2337/diacare.14.11.1050)

Wan C, Fu J, Wang Y, Miao S, Song W \& Wang L 2012 Exosome-related multi-pass transmembrane protein TSAP6 is a target of rhomboid protease RHBDD1-induced proteolysis. PLoS ONE 7 e37452. (doi:10.1371/journal.pone.0037452)

Wang C-Y \& Knutson MD 2013 Hepatocyte divalent metal-ion transporter-1 is dispensable for hepatic iron accumulation and non-transferrin-bound iron uptake in mice. Hepatology 58 788-798. (doi:10.1002/hep.26401)

Wang Y, Lam KS, Kraegen EW, Sweeney G, Zhang J, Tso AW, Chow WS, Wat NM, Xu JY, Hoo RL, et al. 2007 Lipocalin-2 is an inflammatory marker closely associated with obesity, insulin resistance, and hyperglycemia in humans. Clinical Chemistry 53 34-41. (doi:10.1373/ clinchem.2006.075614)

Wang Y, Hodgkinson V, Zhu S, Weisman GA \& Petris MJ 2011 Advances in the understanding of mammalian copper transporters. Advances in Nutrition 2 129-137. (doi:10.3945/an.110.000273)

Wang C-Y, Jenkitkasemwong S, Duarte S, Sparkman BK, Shawki A, Mackenzie B \& Knutson MD 2012a ZIP8 is an iron and zinc transporter whose cell-surface expression is up-regulated by cellular iron loading. Journal of Biological Chemistry 287 34032-34043. (doi:10.1074/jbc.M112.367284)

Wang SB, Lei T, Zhou LL, Zheng HL, Zeng CP, Liu N, Yang ZQ \& Chen XD $2012 b$ Functional analysis and transcriptional regulation of porcine six transmembrane epithelial antigen of prostate 4 (STEAP4) gene and its novel variant in hepatocytes. International Journal of Biochemistry and Cell Biology 45 612-620. (doi:10.1016/j. biocel.2012.12.011)

Wang J, Han L, Wang Z, Ding W, Shang Y, Tang M, Li W, Zhang Y, Zhang W \& Zhong M 2014 Overexpression of STAMP2 suppresses atherosclerosis and stabilizes plaques in diabetic mice. Journal of Cellular and Molecular Medicine 18 735-748. (doi:10.1111/ jcmm.12222)

Wangensteen T, Akselsen H, Holmen J, Undlien D \& Retterstol L 2011 A common haplotype in NAPEPLD is associated with severe obesity in a Norwegian population-based cohort (the HUNT study). Obesity 19 612-617. (doi:10.1038/oby.2010.219)

Weksler-Zangen S, Jorns A, Tarsi-Chen L, Vernea F, Aharon-Hananel G, Saada A, Lenzen S \& Raz I 2013 Dietary copper supplementation restores beta-cell function of Cohen diabetic rats: a link between mitochondrial function and glucose-stimulated insulin secretion.
American Journal of Physiology: Endocrinology and Metabolism 304 E1023-E1034. (doi:10.1152/ajpendo.00036.2013)

Wellen KE, Fucho R, Gregor MF, Furuhashi M, Morgan C, Lindstad T, Vaillancourt E, Gorgun CZ, Saatcioglu F \& Hotamisligil GS 2007 Coordinated regulation of nutrient and inflammatory responses by STAMP2 is essential for metabolic homeostasis. Cell 129 537-548. (doi:10.1016/j.cell.2007.02.049)

Wlazlo N, van Greevenbroek MMJ, Ferreira I, Jansen EHJM, Feskens EJM, van der Kallen CJH, Schalkwijk CG, Bravenboer B \& Stehouwer CDA 2013 Iron metabolism is associated with adipocyte insulin resistance and plasma adiponectin: the Cohort on Diabetes and Atherosclerosis Maastricht (CODAM) study. Diabetes Care 36 309-315. (doi:10.2337/ dc12-0505)

Wu L, Chen X, Zhao J, Martin B, Zepp JA, Ko JS, Gu C, Cai G, Ouyang W, Sen G, et al. 2015 A novel IL-17 signaling pathway controlling keratinocyte proliferation and tumorigenesis via the TRAF4-ERK5 axis. Journal of Experimental Medicine 212 1571-1587. (doi:10.1084/ jem.20150204)

$\mathrm{Xu}$ W, Barrientos T \& Andrews NC 2013 Iron and copper in mitochondrial diseases. Cell Metabolism 17 319-328. (doi:10.1016/ j.cmet.2013.02.004)

Xu HM, Cui YZ, Wang WG, Cheng HX, Sun YJ, Zhao HY \& Yan YQ 2016 Expression and clinical significance of obesity-associated gene STEAP4 in obese children. Genetics and Molecular Research 15 gmr.15048705. (doi:10.4238/gmr.15048705)

Yao Y-G, Kong Q-P, Wang C-Y, Zhu C-L \& Zhang Y-P 2004 Different matrilineal contributions to genetic structure of ethnic groups in the silk road region in china. Molecular Biology and Evolution 21 2265-2280. (doi:10.1093/molbev/msh238)

Yoo SK, Cheong J \& Kim HY 2014 STAMPing into mitochondria. International Journal of Biological Sciences 10 321-326. (doi:10.7150/ ijbs.8456)

Zhang CM, Chi X, Wang B, Zhang M, Ni YH, Chen RH, Li XN \& Guo XR 2008 Downregulation of STEAP4, a highly-expressed TNFalpha-inducible gene in adipose tissue, is associated with obesity in humans. Acta Pharmacologica Sinica 29 587-592. (doi:10.1111/j.17457254.2008.00793.x)

Zhao N, Gao J, Enns CA \& Knutson MD 2010 ZRT/IRT-like protein 14 (ZIP14) promotes the cellular assimilation of iron from transferrin. Journal of Biological Chemistry 285 32141-32150. (doi:10.1074/jbc.M110.143248)

Zhou J, Ye S, Fujiwara T, Manolagas SC \& Zhao H 2013 Steap4 plays a critical role in osteoclastogenesis in vitro by regulating cellular iron/ ROS levels and CREB activation. Journal of Biological Chemistry $\mathbf{2 8 8}$ 30064-30074. (doi:10.1074/jbc.M113.478750)

Received in final form 28 May 2017

Accepted 2 June 2017

Accepted Preprint published online 2 June 2017
() 2017 Society for Endocrinology Printed in Great Britain
Published by Bioscientifica Ltd. 